\title{
Mapping the Connection between Knowledge Transfer and Firm Competitiveness: An Empirical Research in the Basque Country
}

\author{
Javier Benito-Bilbao ${ }^{1 *}$, Francisco Sánchez-Fuente ${ }^{2}$, José Ramón Otegi-Olaso ${ }^{3}$
}

\begin{abstract}
Knowledge transfer (KT) is a wide and complex phenomenon enclosed in the subject of knowledge management which encompasses some related concepts such as knowledge exchange, knowledge sharing, knowledge interfacing and knowledge flow. Presently, KT is one of the most appealing topics in the field of business and economics due to the connection with innovation and business growth that raises the interest and expectancy of diverse institutions and companies on this practice. Many studies about the theme: concept, characteristics and composing elements have been written during the last two decades, and researchers have tried to depict models to represent KT drawing on the different perspectives of the phenomenon, and focused on varied contexts. Connection of knowledge transfer, innovation, and competitiveness has already been revealed, and evidence of a close relationship between effective impact of KT processes, successful innovation, and higher business performance has already been found out. Therefore, identifying the basic keys of the phenomenon of KT which moderate the impact on business competitiveness will become a noteworthy contribution to the business and innovation management field. The aim of this research is to describe the connection between $\mathrm{KT}$ and firm competitiveness through the listing of the main business keys to take into account when planning and performing KT operations. For this purpose, firstly, we develop a conceptual framework of the KT phenomenon, drawing upon a distinguished theoretical KT model which links the determining factors and the impact. Afterwards, we elaborate a survey of questions framed in the model, in order to proceed with an empirical fieldwork based on qualitative interviews with companies and institutions sited in the Basque Country and whose KT activities are frequent and heterogeneous. The qualitative research lets us explain the findings, and state the conclusions of the study, bringing to light a direct link between KT impact and the extent of competitiveness of a company, and revealing a set of main success factors to increase business performance: suitable design and implementation of mechanisms to perform KT, effective cooperation between players, skilled management of the mix of knowledge, and propitious organisational culture.
\end{abstract}

Keywords: Knowledge transfer; firm competitiveness; business performance; knowledge transfer impact; innovation success.

Submitted: August 6th 2015 / Approved: December 4th 2015

\section{Introduction}

Knowledge transfer (KT) is a topic of current interest and fascination which raises debates among the diverse stakeholders involved in this field. All researchers and experts states that it is a core subject of the political agendas of the major industrial countries when developing public programs related to economic growth, entrepreneurship, third mission of the university, innovation, etc.. This is attributed mainly to the double role of KT in the economy: 1) as the prime facilitator to enable conversion of science and technology outcomes in market innovations; 2) as a key role for the generation, deployment and consolidation of organizational units that leverage knowledge, of all sorts of sources, for the improvement, expansion, and profitability of the investments, by extending best practices, disseminating procedures, exchanging data and information, etc ... (Argote and Ingram, 2000, p.164-165).

KT is a complex phenomenon (Bozeman, 2000, p. 627) which could be broken down into a multiple set of elements (Kumar and Ganesh, 2009, p.165-169), and which requires an analysis under diverse streams of research that approach this topic matter (Graham, 2008, p-13-15), since the extensive existing literature draws upon theories on engineering, social sciences and business administration. Therefore, KT could be deemed as a multifactor phenomenon, whose study forces to follow a holistic and eclectic perspective of the issue. Likewise, bibliography points at $\mathrm{KT}$ as a crucial element in economic and social development (Bozeman, 2000, p. 646-647; Bozeman et al, 2015, p. 6), and as the key to improve the competitiveness of companies, institutions, and communities in general. This term is used to stress that various communities are involved: not only business, but all communities. Entities may turn internal and external knowledge into competences after implementing knowledge management policies and processes.

As well, authors have already found evidence about the influence of $\mathrm{KT}$ in achieving successful innovations (Spencer, 2003, p-230-231), and improving business results (Dyer and Nobeoka, 2000, p.364365). Therefore, KT is a business practice with a direct derivative in sustainability and competitiveness of the companies. In fact, the more dependant on knowledge assets is an organization, the more influence KT events have in its viability. Therefore, thanks to the successful impact of a KT operation, a company could attain a unique im-

1 Business Management and Innovation, University of Basque Country. Spain

2 Department of Business Management, Faculty of Engineering, Basque Country University, Spain.

3 Department of Engineering Projects and Graphic Expression, Faculty of Engineering, Basque Country University, Spain.

*Corresponding author: jbenito007@ikasle.ehu.es

ISSN: 0718-2724. (http://jotmi.org)

Journal of Technology Management \& Innovation (c) Universidad Alberto Hurtado, Facultad de Economía y Negocios. 
provement of performance, but when the same company carries out systematic and structured KT activities, which means that this firm underpins knowledge assets as strategic resources (Hoopes and Postrel, 1999, p.838), the competitiveness steadily increases. This theory is particularly appealing for those entities belonging to medium-high and high technological intensity industries, such as biotechnology, information and communication technologies, scientific instrumentation, knowledge-intensive business services, and aeronautics. For all these institutions and firms, the extent of success in their existence and development is closely linked to knowledge assets as principal resources (Grant, 2002, p.145-146)

In parallel, we can find certain business facts described in numerous reports of institutions and associations warning about the existence of a strong elasticity among: the degree of public support for the implementation of research, development and innovation (R\&D\&i), the recruitment of qualified staff, the creation of added-value capacities in companies, and the degree of internationalization, competitiveness, and resistance to situations of crisis or bearish economic cycles. However, other reports, state a lack of proportionality among: the budgetary dimension of public investment in research, development and innovation (R\&D\&i), the amount of scientific production, the volume of registration of intellectual and industrial property, and the set of indicators and metrics about: innovative firms, business competitiveness, export figures, and internationalization ratios. That is, while all stakeholders recognize knowledge as a critical resource, mainly when sourced from scientific origin, for the success of organizations, and macroeconomic impact for society is proved, there is no consensus in addressing solutions to mitigate and redirect those causative roots for not obtaining balance between business performance and budget effort allocated. The European Research Area Committee (ERAC) is a strategic policy advisory committee that advises the Council, the Commission and member states on research and innovation issues that are relevant to the development of the European Research Area. A report thereon issued by the ERAC (2014), and delivered to the Ministry of Economy and Finance of Spain, points to several reasons pertaining to: design of suitable public policies, more efficient cooperation between actors, improving current funding system, and evolving the business culture. It is seen, therefore, that too large amounts of public and private funds dedicated to enterprises and operations around business innovation, unfortunately, does not achieve the final desired goal, because a global KT approach may be required to be highly effective in the impact.

In closing, impact is the final target of any entity performing KT activities and operations, because it entails successful innovations, increase of business performance and, consequently, gaining competitiveness. Achieving satisfactory impact of KT is a direct consequence of the management of the set of its influential and determining factors (Comstock et al, 1999, p.23-24). Thus, verifying the connection between KT and competitiveness, and revealing the specific factors which characterise the optimal administration and execution of the whole KT operations within an entity, would become a priceless instrument to enhance busi- ness performance and firm competitiveness through: a) strengthening business processes; $\mathrm{b}$ ) overcoming goals and business targets.

The aim of this research is to describe the connection between KT and firm competitiveness, following a theoretical and empirical research. The findings and conclusions will allow us to bring to light the direct link between KT impact and the extent of competitiveness of a company, and to reveal the major success factors to increase business performance, through the listing of the main business keys to take into account when planning and performing KT operations.

\section{Methodology}

The research project is composed by three chained phases. Firstly, through a literature search, a globally recognized model of KT which explains the effect of the impact of a KT event is selected, and a conceptual framework associated is developed. Then, as part of the qualitative research, a survey of questions is designed in order to seek the connection between the elements composing the model and the impact attained. Finally, the empirical qualitative research is carried out by means of an analysis based on interviews with stakeholders of innovation management. The study at field level registers observations to confirm or refute the theory developed in the first stage of the investigation, which is embodied in the form of a framework, as representation of the socio economic phenomenon of KT. The research is conducted in a qualitative way, based on survey design techniques, interview execution guidelines, and handling unstructured materials, in order to obtain narrative registers about the analyzed phenomenon. This strategy permits: the exposure and explanation of the phenomenon, the absorption of all sort of feedback, and the analysis of the data collected from direct observation of the phenomenon under study, according to the paradigm of real and natural environment settings (Patton, 2003, p.6; Patton, 2005). The methodology is defined to let increase knowledge and understanding of the fact, and to depict it as a socioeconomic model of, both, theoretical and empirical nature.

At the first stage of the research, we seek a model representing the phenomenon of KT through the basic elements that moderate the result of the process of transferring knowledge, and which, at the same time, depicts the different goals and effectiveness criteria of the each KT process. This model is needed as a tool of information which supports us to define a survey of questions that fit in the dimensions of factors exhibited in the model, and to connect variables of KT performance, with the KT impact. This way, the survey will be complete and no decisive question about a component affecting KT effect will be ignored. With the aim of being precise in our search, we put a set of conditions to ensure that the chosen model is solid enough for our research purpose: 1) the selected model should have global acknowledgement among the scientific community of KT experts; 2) the selected model should have been reviewed and improved through amendments; and 3) the selected model should have been used for research studies, both theoretical in order to develop conceptual frameworks, and empirical in order to apply or define and execute KT experiments. 
We follow the set of recommendations stated by Graham, (2008, p.2426), in order to spot scientific journals that include KT field among the editorial objectives and thematic priorities. The review and analysis of scientific articles allows us to identify a model accomplishing our conditions and premises. The selected model is the model of technology transfer proposed by Bozeman (2000, p. 636), called "contingency effectiveness model of technology transfer", (Bozeman, 2000, p.636), which has also be amended later by the author in the "revised contingent effectiveness model of technology transfer (Bozeman et al, 2015, p.3). This is a well-known and globally accepted model which lets researches and practitioners study technology transfer processes in diverse sciences branches. In fact, Bozeman's model, or the contingent effectiveness model, has been numberless used for researches on the issue, and it has also has been utilized in application, or, as a conceptual framework in a wide variety of articles, ranging from industrial ecology to higher education innovations to transfer of vaccines (Ramakrishnan, 2004; Bailey and Mouton, 2005; Sebastian, 2008; Albors et al, 2009; Mohammed et al, 2010; Hendriks, 2012; Kitagawa and Lightower, 2013). The author himself expresses this fact in the report: Technology Transfer Research and Evaluation: Implications for Federal Laboratory Practice, Final Report to VNS Group, Inc. and the U.S. National Institute of Standards, April 4, 2013. The contingent effectiveness model is representative of the KT socioeconomic phenomenon, and it is showed using a suitable abstraction scale in order to remain represented all types of KT events and potential results.
Thanks to own former research studies carried out, we can explain the main dimensions or master determining factors affecting KT impact (Benito-Bilbao et al, 2015, p. 37-38). These factors, whose characterization has some extent of influence in the celebration of KT and consequently impact on the final outcomes obtained, are (Figure 1):

- Attributes of external context, or characteristics out of the internal framework of a KT event.

- Attributes of the object of knowledge, or characteristics of complexity of the piece of knowledge asset that is subjected to a KT process or operation.

- Attributes of the actors involved in the KT, or senders and receivers of the object of knowledge, who have certain intellectual and emotional features as individuals, and certain organizational and structural features as collectives.

- Attributes of the relationship between actors, or characteristics of the interactions and relations that all the actors play during a KT operation or event.

- Mechanisms of means, as those tools and instruments of all types which carry, support, enable and materialize the operation of a KT event.

- Mechanisms of strategy and corporate management, as those tools and instruments of all types which conduct, guide, handle and steer a KT event.

- Impact, since each KT event leads to a series of results and consequences.

The figure 1, showed below this paragraph, displays a KT phenomenon from the point of view of the dimensions of determinants of impact. Thus, $\mathrm{KT}$ is triggered when actors of certain characteristics commence to keep relationships and interactions activities to let flow a specific object of knowledge. These operations are enabled thanks to a bundle of internal mechanisms which conduct and support the event. All the stated elements distinguish a particular KT phenomenon complemented by the characteristics of the external environment where they are framed. The result of the dynamic of the set of elements is the specific outcomes or impacts of KT phenomenon, and its extent of success is particularly affected due to the interaction of the multiple factors composing each element, denoting KT is a large, complex, multifactor and tangled event (Bozeman, 2000, p.637; Grant, 2002, p.136; Kumar and Ganesh, 2009, p. 165-169; Bozeman et al, 2015, p.1-2).

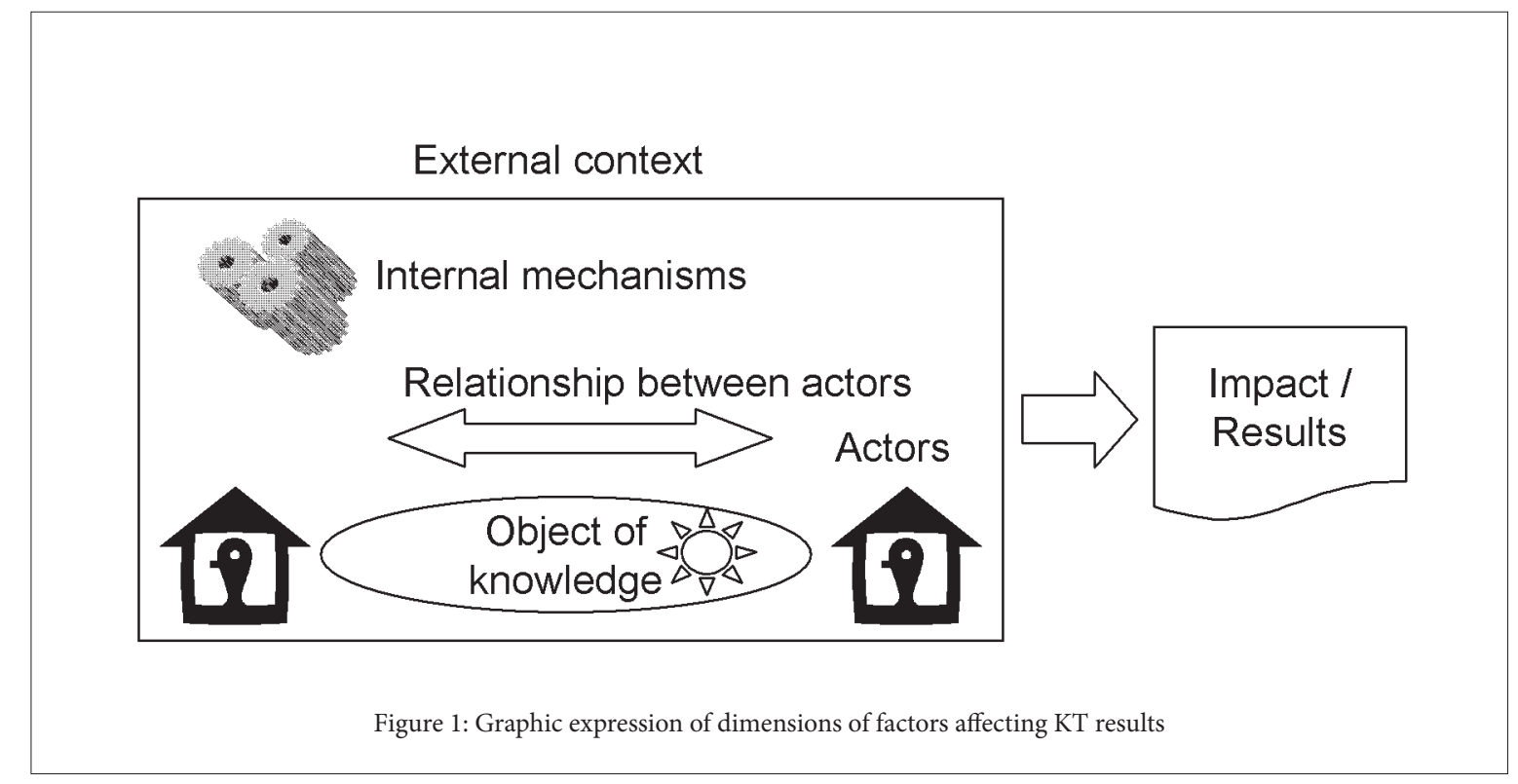

ISSN: 0718-2724. (http://jotmi.org)

Journal of Technology Management \& Innovation @ Universidad Alberto Hurtado, Facultad de Economía y Negocios. 
As stated above, the major descriptors of a KT event are: knowledge, actors, mechanisms, context, and impact. We can interweave Bozeman's model and the descriptors as displayed in Figure 1.

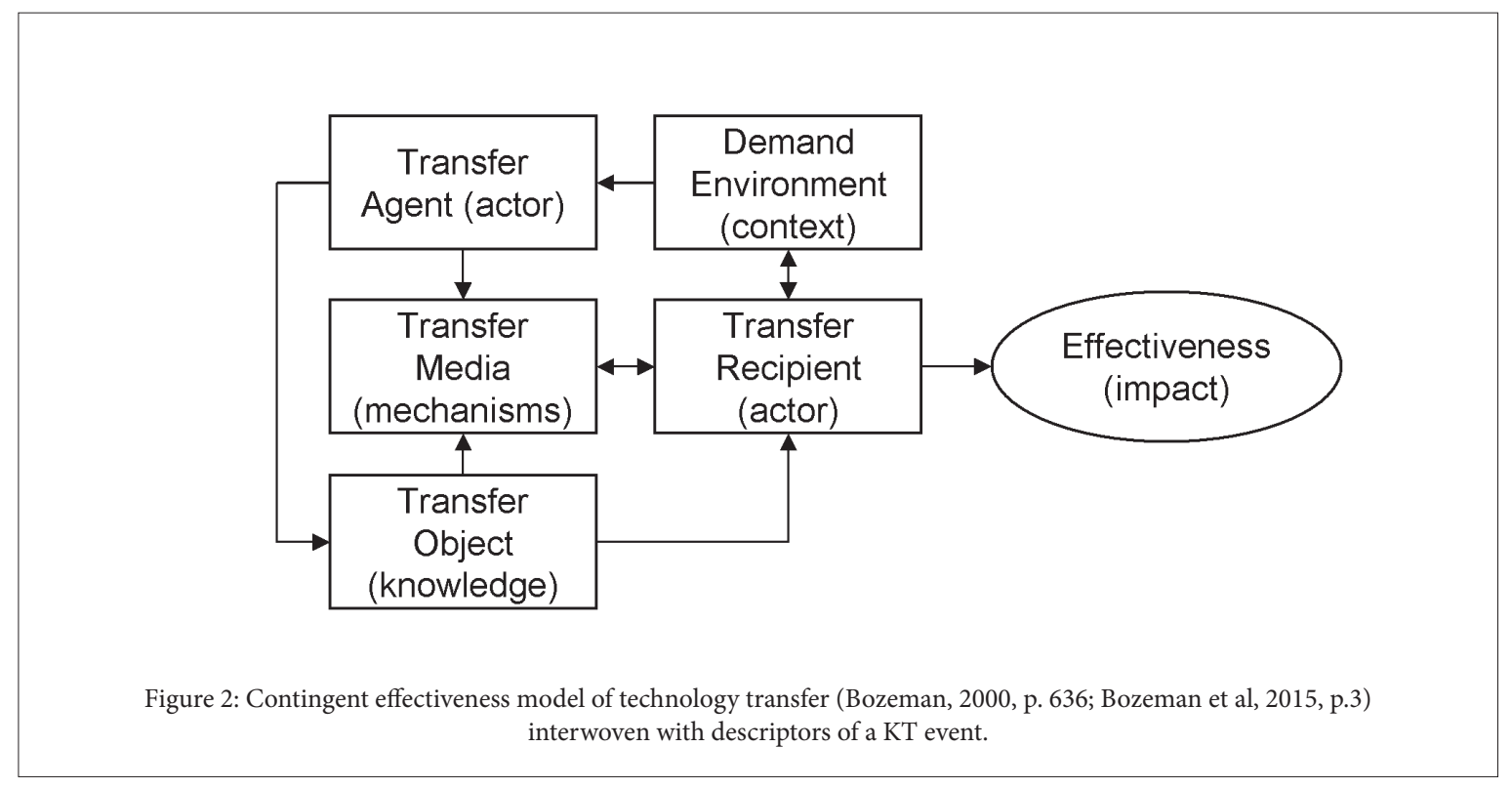

We compare and match the contingent effectiveness model (Bozeman, 2000, p.636; Bozeman et al, 2015, p.3) with our researches on the topic (Table 1), and we display the conceptual framework that we will use for the empirical research (Table 1). This framework, or set of dimensions of determinants which moderates KT impact, is constant to any industry or sector in which the phenomenon happens, because its formulation is characterized by a theoretical nature. It gathers the features defining a KT event: knowledge, actors, mechanisms, context and impact, and also the diverse kinds of impacts for a KT event. Always, the results are consequence of some of the myriad factors included in those dimensions. In conclusion, the qualitative research will be powered by the conceptual framework which is composed by a set of managerial factors comprehensible for the interviewees.

Table 1: Conceptual framework of dimensions for empirical research

Matching Bozeman's model with factors determining KT impact

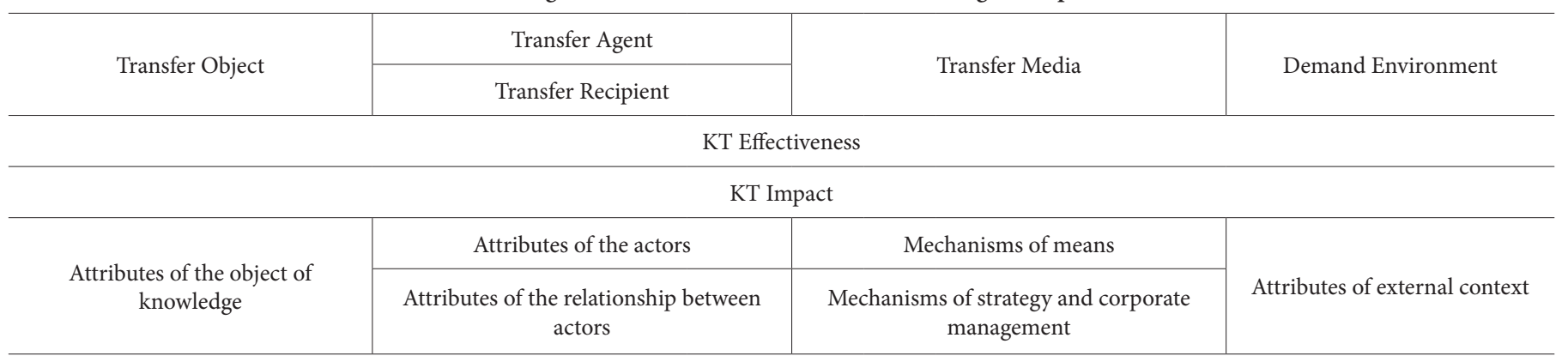

Conceptual framework for the empirical research

\begin{tabular}{l|l|l|l}
\hline Object of knowledge & Actors and relationships & Internal mechanisms & External context \\
\hline \multicolumn{2}{c|}{ Impact } \\
\hline
\end{tabular}

At the second stage of the research, we develop the questions to use during the interviews with the entities involved in the qualitative study. We match each question to the dimension in the conceptual framework in order to ensure that every dimension is fully covered by the inquiring process. The tactic to explore the KT phenomenon is based in the contrast between theoretical dimensions obtained during the first stage of 
the research, and the behavioural characteristics in the real context (Patton, 2002, p.5, p. 11). Interviews are considered social interactions whose aim is to retrieve data for later processing and drawing conclusions (Roulston, 2013, abstract) and the results are descriptions of observed situations and manifestations described by the actors. In order to leverage the power of the interview, the array of questions of the survey should be open enough to let the interviewee explain the details of the empirical experience of the entity when transferring knowledge, but close enough to get the interviewer collect real data of the phenomenon at all levels. So, face-to-face interviews will be aided by a semi-structured survey guide (DiCicco-Bloom and Crabtree, 2006, p.315), in the same environment where KT events happen intensively.

Table 2: Survey of questions for qualitative research interviews

\begin{tabular}{|c|c|}
\hline Question & Dimension \\
\hline Which is the role of KT within the institution/company? & Impact \\
\hline Why is KT a strategic activity for your institution/company? & Impact \\
\hline Which extent of success is the institution/company currently achieving when performing KT events and operations? & Impact \\
\hline Which set of factors are affecting the results of KT? Remark the most influential factors. & All \\
\hline Which is the complexity of the knowledge assets and how do you manage it? & Mechanisms \\
\hline Do you develop internal knowledge and capabilities? Do you capture external knowledge and capabilities? & Mechanisms \\
\hline How do you ensure a successful knowledge transfer inter- and intra organizational? Both? & Mechanisms \\
\hline $\begin{array}{l}\text { Do you effectively observe better business performance (measured through any kind of indicator) when KT is successfully } \\
\text { performed? }\end{array}$ & Impact \\
\hline Do you consider KT results are adding value to the institution/company? How do you perceive the value addition? & Impact \\
\hline Which is the attitude and behaviour of the people of the institution/company towards KT activities? & Actors and relationships \\
\hline Does the company/institution belong to collaborative or cooperative networks with the aim of exploring and exploiting knowledge? & Mechanisms \\
\hline How are the interactions and relationships between you institution/company and other entities when operating KT activities? & Actors and relationships \\
\hline Which concrete improvement, if exists, is KT procuring? & Impact \\
\hline
\end{tabular}

At the third stage of the work, the empirical qualitative research is carried out by means of an assessment and analysis based on interviews with stakeholders of innovation management. The objective of this step is to disclose the connection between the dimensions of factors moderating $\mathrm{KT}$, and the extent of business performance and competitiveness attained. Given that the conceptual framework is simple in appearance but complex in its real content, a qualitative research interview (Flick, 2014) is considered as the most appropriate technique for this stage.

The selection of the group of institutions and companies is done: 1) following the guidelines stated by DiCicco-Bloom and Crabtree (2006, p.316-319) in order to get a homogeneous sample of individuals; and 2) taking into consideration the scope proposed by Etzkowitz and Leydesdorff (2000, p. 111-113) to ensure that the full spectrum of the topic is covered from the diverse approaches, and a heterogeneous vision is achieved. Thus, the panel of respondents exhibits all the social, economic and business environments affected. We select 9 institutions with large empirical and practical KT background, and deeply immersed in an intense KT atmosphere: 3 high-tech clusters representing knowledge-intensive and high technology industries; 2 universities representing the higher education environment and science system, 2 non-profit technology corporations representing research and technology system, and 2 public institutions in charge of fostering innovation representing public policies system. For each institution or company we invite a interviewee, who should be a person of the board of directors (chief executive officer, dean, managing director, etc...) 


\section{Results}

We proceed to the empirical research through a scheduled set of qualitative research interviews with institutions and companies in charge of performing a systematic range of KT events and operations. The aim of the work is to reveal the details of the major keys enabling KT effectiveness, innovation success, and competitiveness of the organisations. The table 3 shows the results obtained after summarizing, processing and tabulating the information captured during the interviews, once allocated according to the dimensions of the framework previously established: object of knowledge, actors and relationships, external context, internal mechanisms, and impact.

Finally, as final fruit of the research process, we reveal the list of empirical factors moderating KT impact, the innovation success and the extent of competitiveness attained by an organisation (Table 4). The factors are classified and categorized according to each dimension of the framework and, also, according to Bozeman's model (Bozeman, 2000, p.636; Bozeman et al, 2015, p.3). Thus, we integrate the results of the research with the theoretical model proposed by Bozeman, conceiving a richer model in terms of lower abstraction of the busi- ness terms described as drivers for KT effectiveness. As Bozeman states (Bozeman, 2000, p. 644-648; Bozeman et al, 2015, p.4-8), effectiveness criteria are dispersed, and could be accomplished due to: market impact, economic development, political reward, public value, and scientific and technical skills, and human capital. Regarding the empirical impact observed by the interviewees, the research results cover the different criteria set by the expert. Thereby, traceability of the complete process is exhibited: from key factors moderating KT effectiveness until competitiveness. The business terms are, indeed, the keys to enable higher business performance and competitiveness for those entities in which knowledge assets act as strategic resources. The competitiveness is attained thanks to successful innovation, and originally, thanks to effectiveness in KT activities. The scheme represented in Figure 3 is the contribution that our study claimed to obtain, along with the empirical evidence brought to light about a close relationship between KT, innovation, business performance, and competitiveness (Hoopes and Postrel, 1999, p.839; Dyer and Nobeoka, 2000, p.364-365; Argote and Ingram, 2000, p.165; Spencer, 2003, p.230-231; Easterby-Smith and Lyles, 2012, p. 15; Ding, 2013, p.101). Therefore, this depiction may become a useful and practical instrument for corporative business management.

Table 3: Results of the qualitative research tabulated according to the conceptual framework

\begin{tabular}{|c|c|c|c|c|c|}
\hline $\begin{array}{l}\text { Type of institution/ } \\
\text { company }\end{array}$ & $\begin{array}{l}\text { Object } \\
\text { of knowledge }\end{array}$ & Actors and relationships & $\begin{array}{l}\text { External } \\
\text { context }\end{array}$ & Internal mechanisms & Impact \\
\hline High-Tech Cluster & $\begin{array}{l}\text { Highly } \\
\text { specialized } \\
\text { knowledge. } \\
\text { Complex } \\
\text { knowledge. }\end{array}$ & $\begin{array}{l}\text { Commitment with KT. High- } \\
\text { tech facilities required. Attitude } \\
\text { towards innovation and } \\
\text { internal/external collaboration. } \\
\text { Partnership-based strategy. } \\
\text { Long-term collaboration. } \\
\text { Bidirectional flows of } \\
\text { knowledge with partners. Joint } \\
\text { ventured relationships. Culture } \\
\text { of common understanding. } \\
\text { Culture of industrialization. }\end{array}$ & $\begin{array}{l}\text { Support of } \\
\text { public policies. } \\
\text { Involvement of } \\
\text { public entities. }\end{array}$ & $\begin{array}{l}\text { Open innovation strategy. Large } \\
\text { networks and multi-profile } \\
\text { actors to enhance cooperation. } \\
\text { Outsourcing strategy for } \\
\text { partnerships an relations. } \\
\text { Contributions structured, } \\
\text { systematized and long-term } \\
\text { addressed. Inter industrial flows of } \\
\text { knowledge. Knowledge value chain } \\
\text { rules the internal organisation. } \\
\text { Intellectual property management. }\end{array}$ & $\begin{array}{l}\text { Increasing individual } \\
\text { and collective capabilities } \\
\text { of the actors. Increasing } \\
\text { overall business } \\
\text { performance of the } \\
\text { institution/company. } \\
\text { Increasing internal } \\
\text { process efficiency. }\end{array}$ \\
\hline High-Tech Cluster & $\begin{array}{l}\text { Knowledge } \\
\text { and } \\
\text { technology } \\
\text { specialized. }\end{array}$ & $\begin{array}{l}\text { Management of human capital } \\
\text { and talent of people. Knowledge } \\
\text { embodied in people. Culture of } \\
\text { technology transfer. }\end{array}$ & & $\begin{array}{l}\text { Strategy to exploit commercially } \\
\text { the scientific knowledge. } \\
\text { Management of intellectual and } \\
\text { industrial property. Structured } \\
\text { and intensive R\&D activities at } \\
\text { corporate level. Integration of KT } \\
\text { into innovation system. }\end{array}$ & $\begin{array}{l}\text { Increasing collaborative } \\
\text { and cooperative capacities. } \\
\text { Increasing innovation } \\
\text { success. Increasing } \\
\text { organisational capabilities. } \\
\text { Increasing value creation } \\
\text { for the market. }\end{array}$ \\
\hline High-Tech Cluster & $\begin{array}{l}\text { Knowledge } \\
\text { structured and } \\
\text { codified for } \\
\text { transferring. }\end{array}$ & $\begin{array}{l}\text { Culture of transfer. Attitude } \\
\text { and aptitude of individuals. } \\
\text { Motivation and commitment } \\
\text { to transfer and innovation. } \\
\text { Hierarchical organization. } \\
\text { Organisational culture to } \\
\text { cooperate. }\end{array}$ & $\begin{array}{l}\text { Socio-economic } \\
\text { value of KT } \\
\text { activities, } \\
\text { innovation and } \\
\text { R\&D. }\end{array}$ & $\begin{array}{l}\text { Science-industry strategy. } \\
\text { Alignment of R\&D and business } \\
\text { operations. Mechanisms to } \\
\text { incentive attitude. Technology } \\
\text { resources to structure and } \\
\text { tangibilize knowledge. Suitable } \\
\text { collaborative models for KT. } \\
\text { Mechanisms to manage KT and } \\
\text { innovation. Methodologies to } \\
\text { measure impact and extent of KT } \\
\text { success. }\end{array}$ & $\begin{array}{l}\text { Increasing organisational } \\
\text { capacities and business } \\
\text { efficiency. }\end{array}$ \\
\hline
\end{tabular}




\begin{tabular}{|c|c|c|c|c|c|}
\hline $\begin{array}{l}\text { Research \& } \\
\text { Technology } \\
\text { Corporation }\end{array}$ & & $\begin{array}{l}\text { Size of the institution. } \\
\text { Background and former } \\
\text { successful experiences of KT. } \\
\text { Structured and systematic } \\
\text { R\&D and innovation activities. } \\
\text { Organisational culture and } \\
\text { commitment to innovation. } \\
\text { Closeness and fluent } \\
\text { interactions with partners. } \\
\text { Climate of reliance and } \\
\text { confidence between actors. }\end{array}$ & & $\begin{array}{l}\text { Cooperation based on partnerships } \\
\text { and long-term relationships. } \\
\text { Scientific-technological } \\
\text { cooperation of actors with diverse } \\
\text { capabilities and expertises. } \\
\text { Planning of R\&D and innovation } \\
\text { strategy commonly designed. } \\
\text { Achieving excellent highly } \\
\text { specialized R\&D outcomes. R\&D } \\
\text { strategy oriented to market and } \\
\text { business needs. }\end{array}$ & $\begin{array}{l}\text { Increasing political and } \\
\text { social culture towards } \\
\text { innovation. Increasing } \\
\text { innovation success. } \\
\text { Increasing quality } \\
\text { of R\&D outcomes } \\
\text { applied to new goods } \\
\text { development. Increasing } \\
\text { competitiveness of the } \\
\text { institution/company. }\end{array}$ \\
\hline $\begin{array}{l}\text { Research \& } \\
\text { Technology } \\
\text { Corporation }\end{array}$ & $\begin{array}{l}\text { Complex } \\
\text { knowledge } \\
\text { assets due to } \\
\text { be composed } \\
\text { by scientific- } \\
\text { technological } \\
\text { and } \\
\text { socioeconomic } \\
\text { elements. }\end{array}$ & $\begin{array}{l}\text { Strategy to share knowledge. } \\
\text { Open innovation and } \\
\text { co-creation approach. } \\
\text { Characteristics of sender and } \\
\text { receiver organizations involved } \\
\text { in KT. }\end{array}$ & $\begin{array}{l}\text { Characteristics of } \\
\text { all KT ecosystem: } \\
\text { public policies; R\&T } \\
\text { system; industry }\end{array}$ & $\begin{array}{l}\text { KT works as a business strategy } \\
\text { tool. R\&D addressed to procure } \\
\text { value to the market. Cooperative } \\
\text { and collaborative approach. } \\
\text { Knowledge management systems. }\end{array}$ & $\begin{array}{l}\text { Increasing social } \\
\text { concern for innovation. } \\
\text { Increasing economic } \\
\text { development. Increasing } \\
\text { sustainability of firms. }\end{array}$ \\
\hline University & & $\begin{array}{l}\text { Culture of transfer. Aligning } \\
\text { academic research plans and } \\
\text { industry needs. Companies } \\
\text { with capacity to absorb } \\
\text { scientific and technological } \\
\text { knowledge. Mutual knowledge } \\
\text { and understanding between } \\
\text { companies and research groups. } \\
\text { Scientists to join companies. }\end{array}$ & $\begin{array}{l}\text { Public science } \\
\text { system structured } \\
\text { and competitive. } \\
\text { Diffusing the } \\
\text { capabilities } \\
\text { of the public } \\
\text { science system. } \\
\text { Improvement and } \\
\text { professionalization } \\
\text { of the entities } \\
\text { supporting KT. }\end{array}$ & $\begin{array}{l}\text { Knowledge generation focused } \\
\text { on business needs. Mobility of } \\
\text { researchers and scientists to } \\
\text { industry. Intellectual and industrial } \\
\text { property management. Enabling } \\
\text { dynamic relations science-industry. }\end{array}$ & $\begin{array}{l}\text { Increasing robustness } \\
\text { of public science } \\
\text { systems. Increasing } \\
\text { collaborative capabilities } \\
\text { between science and } \\
\text { industry. Increasing } \\
\text { base of knowledge about } \\
\text { succeeding in KT and } \\
\text { innovation. }\end{array}$ \\
\hline University & & $\begin{array}{l}\text { Understanding and liaison } \\
\text { between science production } \\
\text { and industry needs. Capabilities } \\
\text { and business acumen to } \\
\text { leverage results of internal and } \\
\text { external scientific research. }\end{array}$ & $\begin{array}{l}\text { Interfacing structures } \\
\text { to foster innovation } \\
\text { and to enable } \\
\text { knowledge flows. } \\
\text { Harmonic and rich } \\
\text { context of basic and } \\
\text { applied knowledge. } \\
\text { Balanced system of } \\
\text { science, industry } \\
\text { and innovation } \\
\text { infrastructures. } \\
\text { Scientific outcomes } \\
\text { available and } \\
\text { accessible to the } \\
\text { industry. Public } \\
\text { instruments to } \\
\text { support KT activities. }\end{array}$ & $\begin{array}{l}\text { Strategy of innovation and } \\
\text { knowledge management. } \\
\text { Implication and commitment to } \\
\text { R\&D and innovation. Abilities and } \\
\text { capacities to operate knowledge- } \\
\text { based activities. Intellectual and } \\
\text { industrial property management. } \\
\text { Systematic and structured } \\
\text { management of KT. Mobility of } \\
\text { scientists to companies. Corporate } \\
\text { strategy to take into account and } \\
\text { adopt scientific research results }\end{array}$ & $\begin{array}{l}\text { Increasing social } \\
\text { commitment and public } \\
\text { awareness for knowledge } \\
\text { development and } \\
\text { innovation. Increasing } \\
\text { management capabilities. } \\
\text { Increasing effectiveness } \\
\text { of application of R\&D } \\
\text { outcomes into new } \\
\text { marketable products. } \\
\text { Increasing organisational } \\
\text { efficiency. }\end{array}$ \\
\hline $\begin{array}{l}\text { Public Policy } \\
\text { Institution }\end{array}$ & $\begin{array}{l}\text { Managing the } \\
\text { complexity } \\
\text { of knowledge } \\
\text { through being } \\
\text { tangible }\end{array}$ & $\begin{array}{l}\text { Organisational culture of } \\
\text { transfer and innovation. Size } \\
\text { of the institution/company. } \\
\text { Motivation and attitude of } \\
\text { human resources. Business } \\
\text { acumen and leadership of } \\
\text { the top management. Fluent } \\
\text { and common understanding } \\
\text { between actors involved in KT. }\end{array}$ & $\begin{array}{l}\text { Funding system for } \\
\text { KT. Programmes } \\
\text { and instruments } \\
\text { developed by } \\
\text { public institutions } \\
\text { supporting KT. } \\
\text { Ecosystem of KIBS } \\
\text { to enable, foster } \\
\text { and enhance KT. } \\
\text { Stimulation of KT } \\
\text { by means of shared } \\
\text { activities among all } \\
\text { stakeholders. }\end{array}$ & $\begin{array}{l}\text { Commitment of the company/ } \\
\text { institution to innovation and KT. } \\
\text { Consistency between business } \\
\text { model and market opportunities/ } \\
\text { needs. Corporative strategy focused } \\
\text { on developing products and services } \\
\text { based on knowledge. Incentive } \\
\text { mechanisms to get people involved } \\
\text { and implicated. Mechanisms to } \\
\text { get effective cooperation between } \\
\text { actors. Knowledge management in } \\
\text { the organization. Management of } \\
\text { intellectual and industrial property. } \\
\text { KT activities structured and } \\
\text { systematized. }\end{array}$ & $\begin{array}{l}\text { Increasing diffusion } \\
\text { of best practices for } \\
\text { innovation success } \\
\text { and competitiveness. } \\
\text { Increasing regional } \\
\text { economic development. } \\
\text { Increasing organisational } \\
\text { capabilities to perform } \\
\text { more successful } \\
\text { innovations. Increasing } \\
\text { socioeconomic } \\
\text { awareness about } \\
\text { innovation and } \\
\text { knowledge. Increasing } \\
\text { competitiveness. }\end{array}$ \\
\hline
\end{tabular}




\begin{tabular}{l|l|l|l|l}
\hline & & & $\begin{array}{l}\text { Increasing individual } \\
\text { capabilities of the } \\
\text { actors. Increasing } \\
\text { cooperative capabilities } \\
\text { of the actors. Increasing } \\
\text { business performance in: } \\
\text { efficiency, profitability, } \\
\text { and competitiveness. } \\
\text { Increase organisational } \\
\text { capabilities to achieve } \\
\text { better innovations for } \\
\text { the market. Increase } \\
\text { Public Policy }\end{array}$ & $\begin{array}{l}\text { Culture of knowledge transfer. } \\
\text { Relationships and links } \\
\text { between scientific entities } \\
\text { and companies. Bidirectional } \\
\text { interactions between science- } \\
\text { industry arenas }\end{array}$ \\
$\begin{array}{l}\text { Increasing organisational } \\
\text { capacities for efficiency. }\end{array}$
\end{tabular}

Table 4: List of empirical factors moderating KT impact, innovation success and competitiveness.

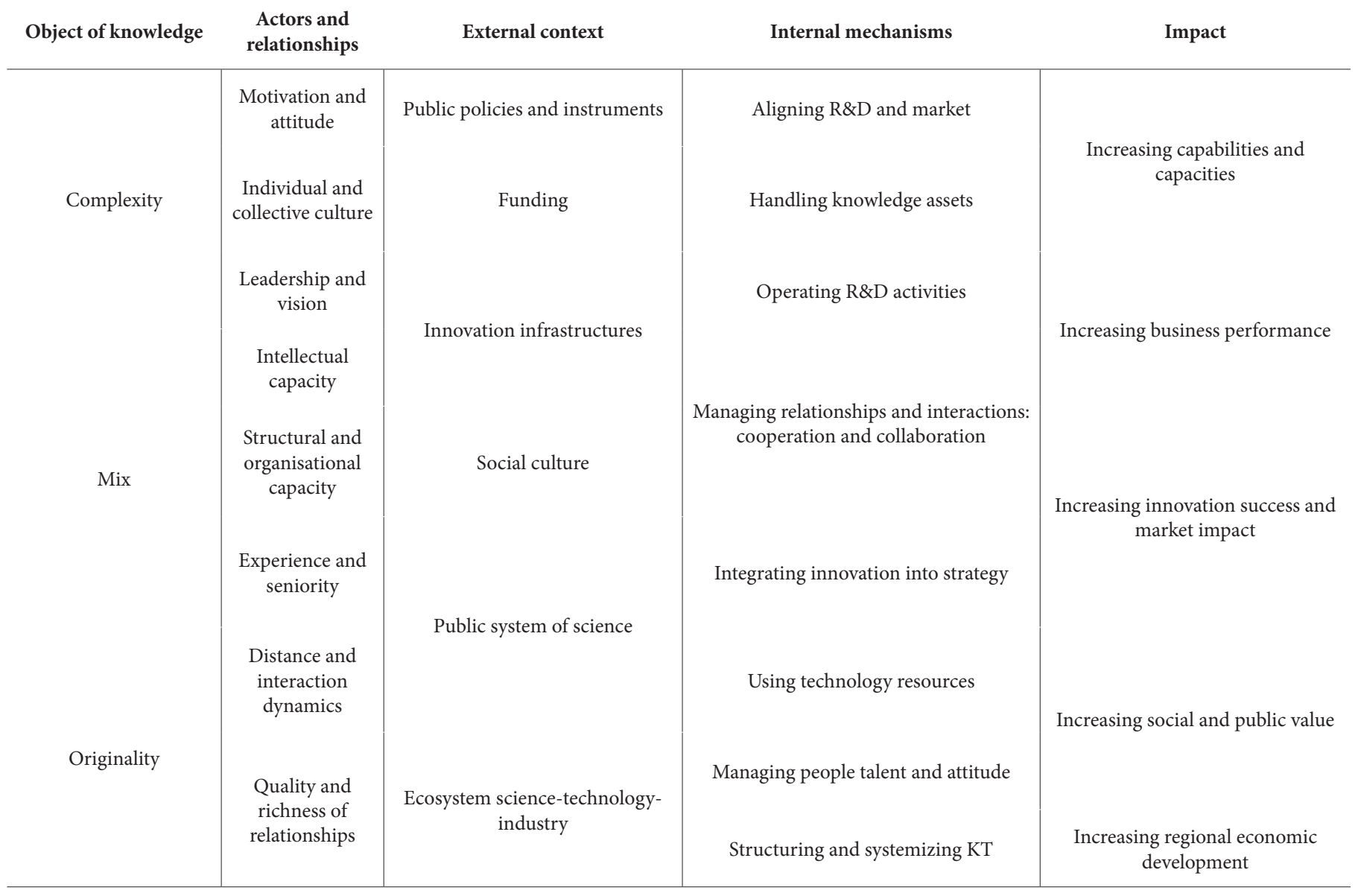




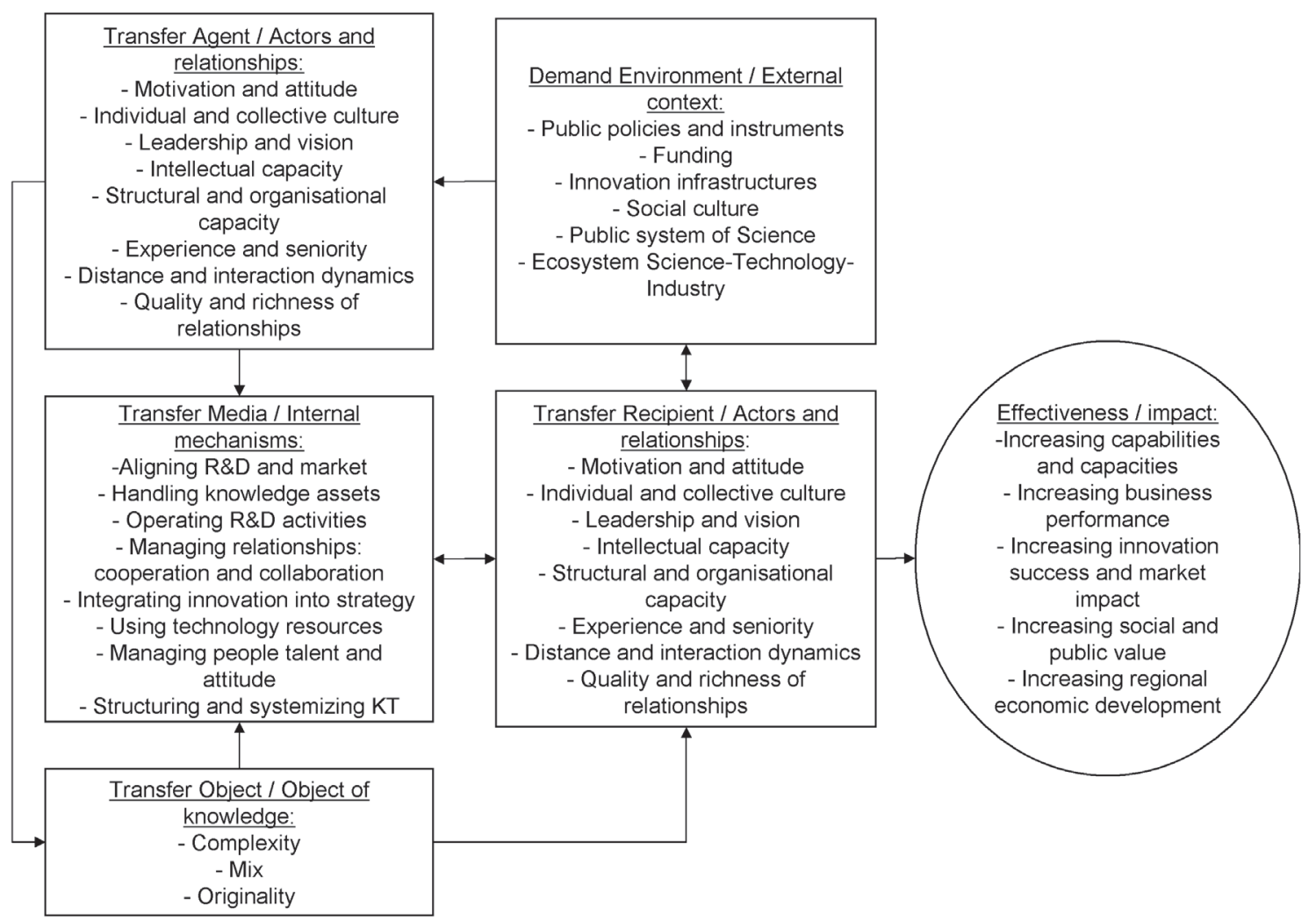

Figure 3: Connection scheme between KT and competitiveness depicted as Bozeman's model enriched with keys for KT effectiveness.

\section{Discussion and implications}

The purpose of the research is to revalidate the evidence of the direct relationship existing between $\mathrm{KT}$, innovation and competitiveness, and also, to disclose the existence of a solid connection between the systemic and steady phenomenon of KT being performed inside a company or institution, and the extent of competitiveness achieved. The aim of the work is also to make available to stakeholders in the field of innovation, a scheme containing the major keys for KT effectiveness, successful innovation and better business performance. The major findings of the research are: ratification of the relationship KT-competitiveness; empirical evidence of that linkage discovered, and furthermore, connection mapped through key business management factors for KT effectiveness. Likewise, we observe that the link is revealed from a qualitative perspective, and thus, the quantitative extent of the relationship between KT and competitiveness should be tackled in future researches.

We have also elaborated a framework of dimensions of KT determinants which is based on characterizing factors of the phenomenon and theoretical evidence of factors moderating the KT impact for high-tech institutions and companies (Benito-Bilbao et al, 2015, p.38). The framework is conceptually analogous to the contingent effectiveness model of technology transfer (Bozeman, 2000, p.636; Bozeman et al, 2015, p.3), showing, therefore, a concordance on the results of both schemes. This finding drives to the fact that the frame of dimensions of determinants covers the same spectrum of KT as the scope represented by the model of characterizing factors for KT. Implication is clear: we can address to the phenomenon of KT from both perspectives as a similar approach. Indeed, the possibility of analyzing and researching on KT from the perspective of dimensions of determinants is more appropriate to define a model for optimal KT, since it allows us to analyze the elements influencing the impact of the phenomenon.

The qualitative research confirms that all the empirical factors responsible of leading a company or institution to innovation success and increasing grade of competitiveness can be allocated among the dimensions of the conceptual framework designed to classify, process and analyze the results of the interviews. Therefore, another finding is that the frame exhibits properly the socio-economic phenomenon of $\mathrm{KT}$, and each KT event is moderated by such mapped factors, so every element has decisive influence on the KT impact, and the extent of effectiveness is dependent on the conditions and circumstances of each 
event or KT operation. As well, there is a short list of factors which are remarked by interviewees as the stronger keys for successful innovation and better business performance when operating KT processes: handling the complexity and the mix of knowledge assets; fostering systematic and intense interactions between actors; deploying a set of internal mechanisms to conduct the phenomenon, and define the KT strategy taking into account of all the perspectives of the situation.

The finding about the relationship between KT and competitiveness is confirmed in the research by all respondents. They all acknowledge that all KT event carried into effect has positive impact in terms of: increasing capabilities, capacities and skills of the individual and collective actors involved; increasing business performance by improving efficiency, reducing costs, etc; increasing innovation success and market impact thanks to the development of new goods fulfilling customers needs; increasing social and public value by means of enhancing awareness of culture of innovation and enlarging stock of knowledge; and increasing regional economic development thanks to the confluence of all benefits in the territory.

The discovery about the set of factors mapping the connexion between $\mathrm{KT}$ and competitiveness is a detailed outcome extracted from the empirical research. According to this finding, we could present these business keys as the dashboard to guide and enable organizations to adopt concrete measures and to optimize events of KT. The major keys detected to increase business performance and gain competitiveness are: 1) steering the organisation with leadership and hybrid vision science-business with the innovation and knowledge as fundamental pillars; 2) managing the talent and the motivation of the people to set a prone attitude and innovation culture; 3) structuring and systematizing KT to create the suitable scenario with resources and skills; 4) increasing the awareness of the organization with R\&D activities and knowledge management to create goods, to develop further individual and collective capabilities, and to store experience and expertise; 5) managing interactions and relationships around the collaboration and cooperation to extend the scope of possibilities; 6) handling the complexity and the mix of knowledge assets; and 7) harnessing the external context of instruments and policies for the self benefit.

\section{Conclusions}

$\mathrm{KT}$ is a phenomenon strongly linked to innovation and competitiveness which can be studied under two different approaches: characterizing factors, or determinants of its impact. The last is a most suitable technique to reveal the key elements which more influence have on the effectiveness of the KT events, and, thus, more intensely affect on the achievement of better business performance and increase of competitiveness. These key factors can be classified in accordance with the dimensions characteristics of KT and its effectiveness: knowledge, actors, mechanisms and external context. We disclose empirical evidence about a positive relationship between KT effectiveness and better business performance, and we present a scheme with the levers liable to turn KT activities into competitiveness: leadership and vision in innovation, talent of the people, organisational culture, systematic
R\&D and knowledge management activities, capabilities and experience, collaboration and cooperation complexity and mix of knowledge assets, and external instruments and policies.

Multiple stakeholders in the field of innovation and business management may take advantage of the findings and implications. KT is a crucial management practice linked to competitiveness which should be seriously adopted by all companies and institutions living inside a knowledge-based atmosphere. Corporations and SMEs should gain awareness about KT, and particularly knowledge-intensive business services companies should lead the implementation of systems related to the set of key factors. Public institutions and policy makers should develop instruments and programmes in order to ensure that the key factors are understood and customized according to each reality. Innovation infrastructures should promote partnerships and networks to explore and exploit knowledge. Science system and universities should align $\mathrm{R} \& \mathrm{D}$ activities with market needs and trends, balancing basic and applied research. Finally, researchers on business management might progress in the study of KT issue and conduct empirical studies of statistical nature to validate of the extent of influence of each factor.

\section{Acknowledgement}

Dr. Javier Benito-Bilbao (Ph.D.) is the corresponding author of the scientific article "Mapping the connection between knowledge transfer and firm competitiveness: an empirical research in the Basque Country". The writer holds a Ph.D., a M.B.A, a M.Sc., and a B.Sc. and a background of 17 years at management consulting firms, research centres and universities, and high-tech corporations acting as consultant and manager. Presently, the author is an independent consultant and researcher on business management and innovation, as well as, author and reviewer of scientific articles in the field of business management and innovation. The article is an outcome of the theoretical and empirical doctoral research process developed by the writer, whose aim was to design a model for optimal transfer of knowledge within Basque high-tech manufacturing and developing industries. The thesis was awarded Cum Laude in February 2015 after a doctorate process supervised by Dr. Francisco Sánchez-Fuentes (Ph.D.) and Dr. José Ramón Otegi-Olaso (Ph.D.), according to the terms and conditions of the Project Management - Euro MPM academic programme of the Department of Project Engineering and Graphic Expression of the Faculty of Engineering of the University of the Basque Country in Bilbao, Alameda Urquijo s/n, 48013, Bilbao (SPAIN).

The author notes that there is no conflict of interest, including any financial, personal or other relationship with third parties, other people or organizations that could inappropriately influence, or be perceived to influence this work. Likewise, there was no financial support for the conduct of the research and for the preparation of the article.

\section{References}

Albors-Garrigos, J., Hervas-Oliver, J. L., \& Hidalgo, A. (2009). Analysing high technology adoption and impact within public 
supported high tech programs: An empirical case. The Journal of High Technology Management Research, 20(2), 153-168. doi: 10.1016/j. hitech.2009.09.006

Al-Gharibeh, K. M. (2011). The knowledge enablers of knowledge transfer: an empirical study in telecommunications companies. IBIMA Business Review, Vol 2011, Article ID 328944, 1-13. doi: $10.5171 / 2011.328944$

Anokhin, S., Wincent, J., \& Frishammar, J. (2011). A conceptual framework for misfit technology commercialization. Technological Forecasting and Social Change, 78(6), 1060-1071. doi:10.1016/j. techfore.2010.12.005

Argote, L., \& Ingram, P. (2000). Knowledge transfer: A basis for competitive advantage in firms. Organizational Behavior and Human Decision Processes, 82(1), 150-169. doi:10.1006/obhd.2000.2893

Bailey, T., \& Mouton, J. (2005). A review of models of research utilisation (Vol. 1). AFRICAN SUN MeDIA;

Becker, M. C., \& Knudsen, M. P. (2006). Intra and inter-organizational knowledge transfer processes: Identifying the missing links. Danish Research Unit for Industrial Dynamics. Working Paper (No. 06-32), Copenhagen Business School.

Benito-Bilbao J., Sánchez-Fuente F. Otegi-Olaso J.R. (2015). Holistic model for an efficient knowledge transfer of high-tech firms. International Journal of Business and Innovation. 2(5), 1-26.

Bosch-Sijtsema, P. M., \& Postma, T. J. (2010). Governance factors enabling knowledge transfer in interorganisational development projects. Technology Analysis \& Strategic Management, 22(5), 593608. doi:10.1080/09537325.2010.488064

Bozeman, B. (2000). Technology transfer and public policy: a review of research and theory. Research Policy, 29(4), 627-655. doi:10.1016/ S0048-7333(99)00093-1

Bozeman, B., Rimes, H., \& Youtie, J. (2015). The evolving state-ofthe-art in technology transfer research: Revisiting the contingent effectiveness model. Research Policy, 44(1), 34-49. doi:10.1016/j. respol.2014.06.008

Comstock, G. L., \& Sjolseth, D. E. (1999). Aligning and Prioritizing Corporate RD. Research-Technology Management, 42(3), 19-25.

DiCicco-Bloom, B., \& Crabtree, B. F. (2006). The qualitative research interview. Medical education, 40(4), 314-321. doi:10.1111/j.13652929.2006.02418.x

Ding, Q. (2013). Inter-Partner Interactions and Knowledge Transfer Mechanisms in the Chinese Automotive Industry: A Qualitative Research Based on Dual Managerial Perceptions. International Journal of Management and Business Research, 3(2), 89-105.

Dyer, J., \& Nobeoka, K. (2002). Creating and managing a high performance knowledge-sharing network: the Toyota case. Strategic Management Journal 21(3): 345-367. doi: 10.1002/(SICI)10970266(200003)21:3<345::AID-SMJ96>3.0.CO;2-N
Easterby-Smith, M. and Lyles, M. A. (2012) The Evolving Field of Organizational Learning and Knowledge Management, in Handbook of Organizational Learning and Knowledge Management (eds M. Easterby-Smith and M. A. Lyles), John Wiley \& Sons, Inc., Hoboken, NJ, USA. doi: 10.1002/9781119207245.ch1

Eckl, V. C. (2012). Creating an Interactive-Recursive Model of Knowledge Transfer. Working Paper submitted at Danish Research Unit for Industrial Dynamics, Summer 2012 Conference. CBS, Copenhagen, Denmark.

European Research Area and Innovation Committee (2014). ERAC Peer Review of the Spanish Research and Innovation System. Final report, August 2014. Retrieved from: https://ec.europa.eu/research/ innovation-union/pdf/erac/es_peer_review_report_2014.pdf

Etzkowitz, H., \& Leydesdorff, L. (2000). The dynamics of innovation: from National Systems and "Mode 2" to a Triple Helix of universityindustry-government relations. Research policy, 29(2), 109-123. doi:10.1016/S0048-7333(99)00055-4

Fang, S. C., Yang, C. W., \& Hsu, W. Y. (2013). Inter-organizational knowledge transfer: the perspective of knowledge governance. Journal of Knowledge Management, 17(6), 943-957. doi: http://dx.doi. org/10.1108/JKM-04-2013-0138

Flick, U. (2014). An introduction to qualitative research. Sage

Graham P.J. (2008, January). Knowledge Transfer in Theory and Practice: A Guide to the Literature. Social Research Unit, Department of Sociology, University of Saskatchewan, Saskatoon, Canada. Retrieved from: http://www.academia.edu/1962622/Knowledge_ Transfer_in_Theory_and_Practice_A_Guide_to_the_Literature

Grant, R. M. (2002). The knowledge-based view of the firm. In Choo, C. W., \& Bontis, N. (2002). The strategic management of intellectual capital and organizational knowledge. (pp. 133-148) Oxford University Press, 2002 - Business \& Economics.

Hendriks, J. (2012). Technology transfer in human vaccinology: a retrospective review on public sector contributions in a privatizing science field. Vaccine, 30(44), 6230-6240. doi:10.1016/j. vaccine.2012.07.087

Hoopes, D. G., \& Postrel, S. (1999). Shared knowledge,"glitches," and product development performance. Strategic Management Journal, 20(9), 837-865.doi: 10.1002/(SICI)1097-0266(199909)20:9<837::AIDSMJ54>3.0.CO;2-I

Wan, J., Liu, Q., Li, D., \& Xu, H. (2010). Research on Knowledge Transfer Influencing Factors in Software Process Improvement. Journal of Software Engineering and Applications, 3(02), 134-140. doi:10.4236/jsea.2010.32017

Kitagawa, F., \& Lightowler, C. (2013). Knowledge exchange: A comparison of policies, strategies, and funding incentives in English and Scottish higher education. Research Evaluation, 22(1), 1-14. doi: $10.1093 /$ reseval/rvs035 
Kumar, J. A., \& Ganesh, L. S. (2009). Research on knowledge transfer in organizations: a morphology. Journal of Knowledge Management, 13(4), 161-174. doi: http://dx.doi.org/10.1108/13673270910971905

Mohammed, Y., Sax, U., Dickmann, F., Lippert, J., Solodenko, J., Voigt, G., \& Rienhoff, O. (2010). On Transferring the Grid Technology to the Biomedical Community. Studies in Health Technology Information, Vol. 159, 28-39. doi: 10.3233/978-1-60750-583-9-28

Patton, M. Q. (2003). Qualitative evaluation checklist. Evaluation Checklists Project. Evaluation. Checklists Project. Retrieved from: http://dmeforpeace.org/sites/default/files/Patton_Qualitative\%20 Evaluation\%20Checklist.pdf

Patton, M. Q. (2005). Qualitative research. Encyclopedia of Statistics in Behavioral Science. doi: 10.1002/0470013192.bsa514

Paulin, D. \& Suneson, K. (2012). Knowledge transfer, knowledge sharing and knowledge barriers-Three blurry terms in KM. The Electronic Journal of Knowledge Management, 10(1), 81-91.
Ramakrishnan, S. (2004). An industrial ecology framework to assist transferring environmental technologies. International Journal of Technology Transfer and Commercialisation, 3(2), 147-165. doi: 10.1504/IJTTC.2004.004606

Roulston, K. (2013). Interviews in Qualitative Research. The Encyclopedia of Applied Linguistics. DOI: 10.1002/9781405198431. wbeal0572

Sebastian, J. (2008). The knowledge transfer in the cooperation for development. Arbor-Ciencia Pensamiento y Cultura, 184(732), 719728. doi: 10.3989/arbor.2008.i732.217

Spencer, J. W. (2003). Firms' knowledge sharing strategies in the global innovation system: empirical evidence from the flat panel display industry. Strategic Management Journal, 24(3), 217-233. DOI: $10.1002 / \mathrm{smj} .290$ 